\title{
The Edge Crack, Texture Evolution, and Mechanical Properties of Mg-1Al-1Sn-Mn Alloy Sheets Prepared Using On-Line Heating Rolling
}

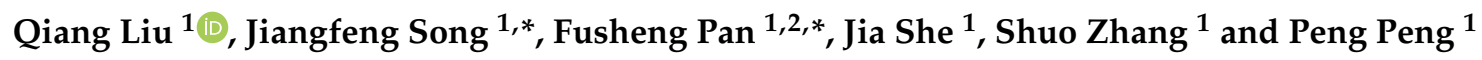 \\ 1 National Engineering Research Center for Magnesium Alloy, Chongqing University, Shazhengjie 174\#, \\ Shapingba District, Chongqing 400045, China; LQ2603957040@hotmail.com (Q.L.); jiashe@foxmail.com (J.S.); \\ shuosurezs@163.com (S.Z.); peng_pp@foxmail.com (P.P) \\ 2 Chongqing Academy of Science and Technology, Chongqing 401123, China \\ * Correspondence: jiangfeng.song@cqu.edu.cn (J.S.); fspan@cqu.edu.cn (F.P.); Tel.: +86-182-2361-6225 (J.S.); \\ $+86-137-0832-8273$ (F.P.)
}

Received: 23 September 2018; Accepted: 12 October 2018; Published: 22 October 2018

\begin{abstract}
A series of Mg-1Al-1Sn-Mn magnesium alloy sheets were rolled from $3 \mathrm{~mm}$ to $1 \mathrm{~mm}$ under temperatures of $150{ }^{\circ} \mathrm{C}, 200^{\circ} \mathrm{C}$, and $250^{\circ} \mathrm{C}$ in four rolling passes using on-line heating rolling. The conventional rolling was also performed for comparison. Scanning electron microscopy (SEM) and electron backscatter diffraction (EBSD) technologies were utilized to characterize the edge cracks as well as the microstructure of rolled thin sheets. The result revealed that the number of edge cracks decreased dramatically with the increase of rolling temperature. No visible edge cracks were found on the surface of sheets rolled at $250{ }^{\circ} \mathrm{C}$ by on-line heating rolling, while the conventional rolling at the same temperature still resulted in severe edge cracks. The intensity of the basal texture for on-line rolled sheets increased from 4.982 to 9.596 as the rolling temperature increased from $150{ }^{\circ} \mathrm{C}$ to $250{ }^{\circ} \mathrm{C}$, which was related to the reorientation of new grains and deformation grains remained after rolling. The direction of the basal pole slightly tilted towards the rolling direction (RD), which may be mainly attributed to the activation of a pyramidal slip, as well as the tension imposed on the samples. Moreover, mechanical properties were improved after rolling on the basis of the strong texture and grain refinement. The highest yield strength (YS), ultimate tensile strength (UTS), and the maximum elongation of the rolled sheets were $148 \mathrm{MPa}, 298 \mathrm{MPa}$, and 14.6\% along the RD, respectively.
\end{abstract}

Keywords: metallic alloy; edge crack; on-line heating rolling; texture; mechanical properties

\section{Introduction}

Magnesium and its alloys are regarded to be one of the most useful structural materials in the 21st century, owing to its low density, high specific strength, excellent electromagnetic shielding, and ease of recycling, which can be widely applied in the fields of 3C, automotive, aerospace, etc. However, magnesium alloys are still facing great challenges to be further industrialized due to its low formability and corrosion resistance at room temperature [1-5]. According to the von Mises criterion, the metal requires at least five independent slip systems to perform good formability [6,7]. However, $\mathrm{Mg}$ alloys with an hcp structure can only provide two independent slip systems at room temperature $[8,9]$.

Many researchers attempt to activate more non-basal slips and dynamic recrystallization (DRX), which can remarkably improve formability of magnesium alloys [10]. However, it is difficult for hcp metal to activate the non-basal slips (normally prismatic and pyramidal slip) due to their high critical resolved shear stress (CRSS) at room temperature [11,12]. The most effective approach put forward by scientists to reduce the CRSS is increasing the processing temperature, which can also simultaneously facilitate the DRX. Catorceno et al. [13] proved that the remarkable DRX would occur during rolling at 
elevated temperatures. The stacking fault energy and microstructure softening mechanisms also affect the formability at elevated temperature. Wang et al. [14] showed that the stacking fault energies of Mg-Al-based alloys are reduced by the addition of Sn, which results in the improvement of workability for the alloys. Saboori et al. [15] revealed that typical flow softening behavior would appear in some metallic alloys once they were subjected to warm working under the effect of the adiabatic deformation heating or strain localization. On-line heating rolling (ON-LHR) proposed by Pan et al. [16] provides in situ heating which accelerates the deformation of magnesium alloys. The concept of ON-LHR is to heat the sheets and working rollers simultaneously. There is no need to anneal the sheets between passes compared with the conventional rolling.

The recent developed Mg-Al-Sn-Mn system alloy has attracted much attention due to its better formability and comparable cost to AZ31. Such an alloy has great potential to be commercialized as the structure materials in working environment like AZ31 plates. She et al. [17] have investigated the mechanical properties of extruded Mg-Al-Sn-Mn alloy bars. It is reported that ATM110 bars extruded under the extrusion temperature of $250{ }^{\circ} \mathrm{C}$ exhibited a yield strength of $260 \mathrm{MPa}$, an ultimate tensile strength of $290 \mathrm{MPa}$, and an elongation of $18 \%$. In addition, Guan et al. [18] also studied the relevant properties of an as-cast and as-extruded Mg-Al-Sn-Mn alloy using an orthogonal experimental design. However, the rolling behavior of AT11M alloy has not been reported and the rollability of this alloy by on-line heating rolling has not been carried out. Thus, in the present work, the on-line heating rolling experiment was performed on the Mg-1Al-1Sn-Mn alloys with a large pass reduction of $25 \%$ at temperatures ranging from $150{ }^{\circ} \mathrm{C}$ to $250{ }^{\circ} \mathrm{C}$. The edge crack and texture evolution of the rolled sheet at different temperatures were investigated.

\section{Materials and Methods}

The cast ingot in this work was prepared using an electrical resistance furnace (Experimental electric furnace factory, Shanghai, China). Pure $\mathrm{Mg}$, pure $\mathrm{Al}$, pure $\mathrm{Sn}$, and a $\mathrm{Mg}$-Mn master alloy were added at $740{ }^{\circ} \mathrm{C}$ under the mixed atmosphere of $\mathrm{CO}_{2}$ and $\mathrm{SF}_{6}$. Then, the melt was kept at $740{ }^{\circ} \mathrm{C}$ for $20 \mathrm{~min}$, and then poured into a mild steel crucible preheated at $350^{\circ} \mathrm{C}$ and air cooled. The as-cast billet with a diameter of $80 \mathrm{~mm}$ and a height of $95 \mathrm{~mm}$ was a solution treated at $500{ }^{\circ} \mathrm{C}$ for $24 \mathrm{~h}$. Subsequently, an X-ray fluorescence (XRF) test (Shimadzu Corporation, Kyoto, Japan) was conducted on the ingot and the resulting chemical composition found is listed in Table 1 . The ingots were extruded at $370{ }^{\circ} \mathrm{C}$ into plates with $60 \mathrm{~mm}$ in width (TD) and $3 \mathrm{~mm}$ in thickness (ND) with an extrusion ratio of 28:1, the picture of extruded plates and its metallographic graph are shown in Figure 1. These extruded plates were used as the raw materials for rolling.

Table 1. Chemical composition of the AT11M alloy (wt \%).

\begin{tabular}{cccccccc}
\hline AT11M & Al & Sn & Mn & Si & Fe & Zn & Mg \\
\hline Sample & 0.87 & 0.86 & 0.49 & 0.04 & 0.01 & 0.01 & Bal. \\
\hline
\end{tabular}

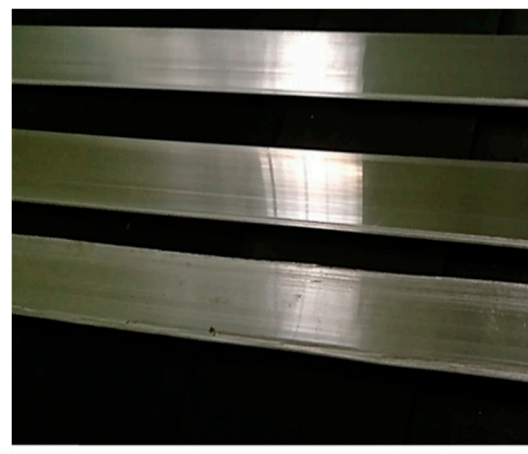

(a)

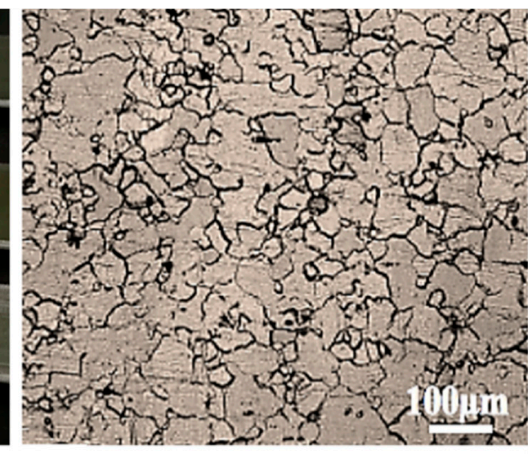

(b)

Figure 1. (a) The picture of extruded plates. (b) The metallographic graph of an extruded plate. 
The extruded plates were rolled by the on-line heating rolling under three different temperatures $\left(150{ }^{\circ} \mathrm{C}, 200{ }^{\circ} \mathrm{C}\right.$, and $\left.250{ }^{\circ} \mathrm{C}\right)$. As is depicted in Figure 2, the recently developed rolling equipment mainly consisted of three systems including a stretching device to give the sample tension at both ends, a rolling device, and a heating device to heat the sheets in situ. There was a four-roller rolling mill that was made up of the support rollers and work rollers of $320 \mathrm{~mm}$ and $120 \mathrm{~mm}$ in diameter, respectively. The main concept of this equipment was to heat the sheet (by resistance heating) simultaneously with the work rollers (by oil heating). The temperature of the sheet was controlled by thermocouples, as shown in Figure 2. Generally, this equipment enabled continuous rolling through the following process: the sheet was first clamped by the stretching device and then heated to the set temperature. In this work, the rolling was designed such that the sheet was rolled unidirectionally. The sheet was rolled in four passes in total without annealing between passes and the total reduction was kept at around $67 \%$, with the detailed process parameters shown in Table 2 . The rollers were heated to $200{ }^{\circ} \mathrm{C}$ before rolling. The sheets were also prepared by conventional rolling at $150{ }^{\circ} \mathrm{C}-250{ }^{\circ} \mathrm{C}$ using four passes with the same reduction per pass of $25 \%$. The sheets were then annealed at the corresponding rolling temperature for $15 \mathrm{~min}$ between passes.

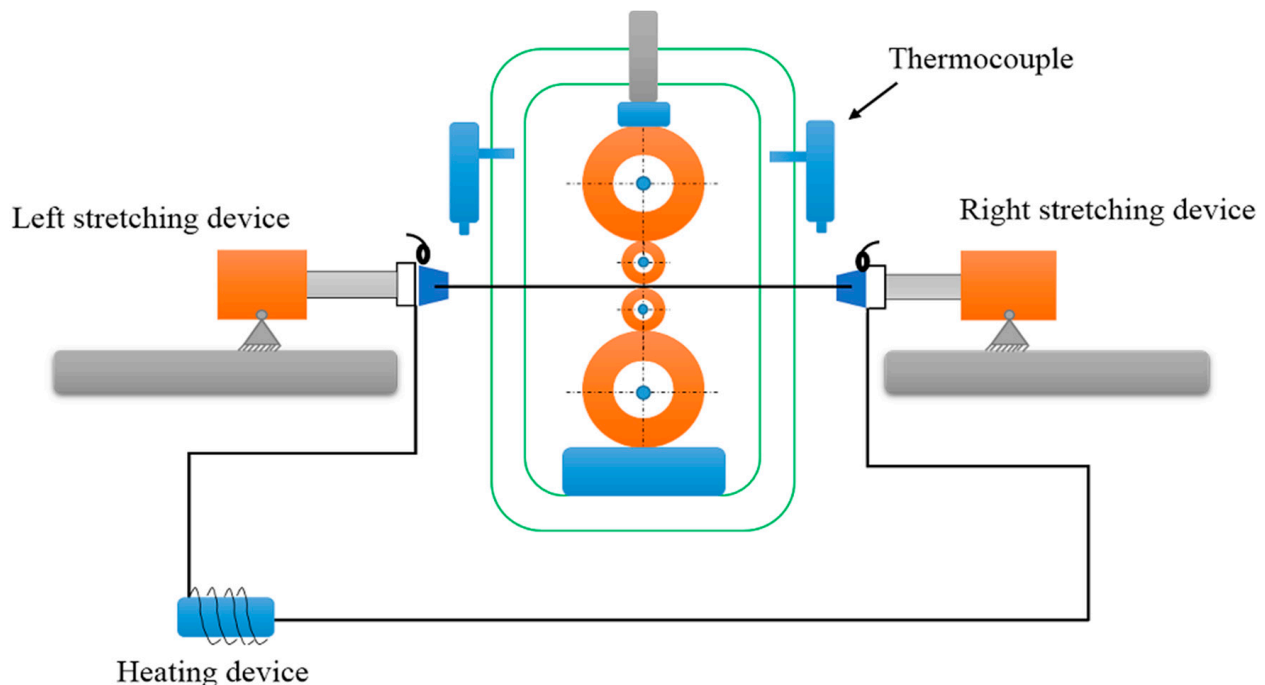

Figure 2. Schematic diagram of the on-line heating rolling machine.

Table 2. The detailed parameters of on-line heating rolling process.

\begin{tabular}{cccccc}
\hline $\begin{array}{c}\text { Temperature } \\
\left({ }^{\circ} \mathbf{C}\right)\end{array}$ & $\begin{array}{c}\text { Reduction } \\
(\text { per Pass/\%) }\end{array}$ & $\begin{array}{c}\text { Initial Thickness } \\
(\mathbf{m m})\end{array}$ & $\begin{array}{c}\text { Final Thickness } \\
(\mathbf{m m})\end{array}$ & $\begin{array}{c}\text { Roll Speed } \\
(\mathbf{m m} / \mathbf{s})\end{array}$ & $\begin{array}{c}\text { Tension } \\
\mathbf{( k N )}\end{array}$ \\
\hline 150 & 25 & 3.02 & 0.99 & 0.05 & 1.5 \\
200 & 25 & 2.97 & 0.95 & 0.05 & 1.5 \\
250 & 25 & 2.94 & 0.93 & 0.05 & 1.5 \\
\hline
\end{tabular}

The sheets were initially observed with naked eyes to check the edge crack and surface quality of sheets. The number of edge cracks were counted and the maximum depth of each crack was measured. The microstructure of the rolled sheets were examined using optical microscopy (OM) (MDS, OPTEC, Chongqing, China). A scanning electron microscope (SEM) (VEGA 3 LMH, TESCAN, Brno, Czech Republic) was also employed to observe the fracture surfaces of the edge cracks. In order to obtain the crystal orientation and misorientation angle distribution, electron back scattered diffraction (EBSD) (JSM-7800F, JEOL, Tokyo, Japan) was also used for characterization using the field emission scanning electron microscope (JSM-7800F, JEOL, Tokyo, Japan) equipped with the EBSD system. The operating voltage was $20 \mathrm{kV}$ and the step size was $0.5 \mu \mathrm{m}$. Sample preparation, which consisted of grinding on SiC papers (200 \#, 400 \#, 800 \#, 1000 \#, 1600 \#, and 2000 \#), washing, blow-drying, and electropolishing was carried out with an $\mathrm{AC}_{2}$ solution for EBSD samples using a voltage of $20 \mathrm{~V}$ 
for $60 \mathrm{~s}$ under a temperature of $-20^{\circ} \mathrm{C}$. Meanwhile, tensile tests were also performed using the AG-XD (AG-X50kND, Shimadzu Corporation, Kyoto, Japan) plus, 20 kN-50 kN machine with a tensile rate of $0.5 \mathrm{~mm} / \mathrm{s}$. The specimens for the tensile test with a gauge length of $12 \mathrm{~mm}$ and width of $3 \mathrm{~mm}$ were machined from the roll sheets along $0^{\circ}, 45^{\circ}$, and $90^{\circ}$ to the rolling direction.

\section{Results}

\subsection{Rolling Feasibility}

The surface appearance of the rolled specimen sheets using on-line heating and conventional rolling under different temperatures is compared in Figure 3. The rolling feasibility of the rolled sheets was characterized by the number of edge cracks and the maximum crack depth. It can be seen clearly that plenty of large edge cracks were present at low temperatures for both kinds of rolling process. At the same rolling temperature, the sheets rolled using on-line heating rolling exhibited fewer and smaller edge cracks than the conventionally rolling. For instance, no visible edge cracks were observed at $250^{\circ} \mathrm{C}$ with on-line heating rolling, as displayed in Figure 3c, while a few edge cracks were still visible at the same temperature after conventional rolling, as shown in Figure $3 f$. In addition, the numbers and the depth of edge cracks diminished with increasing temperature. Besides, it was obtained that the edge cracks vanished more effectively at high temperatures in on-line heating rolling than in conventional rolling.

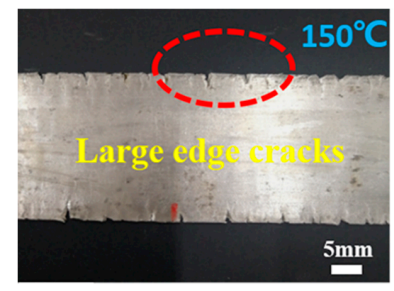

(a)

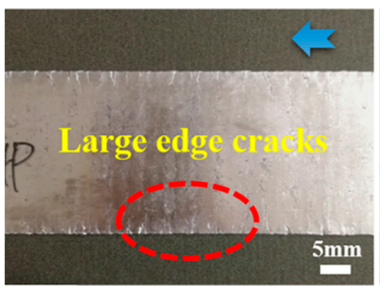

(d)

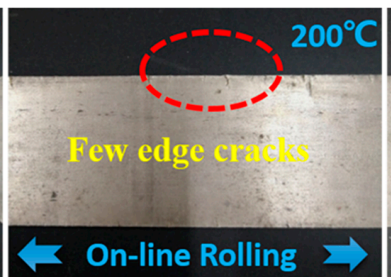

(b)

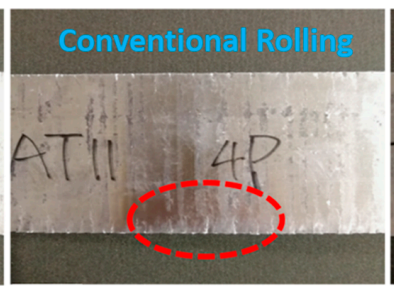

(e)

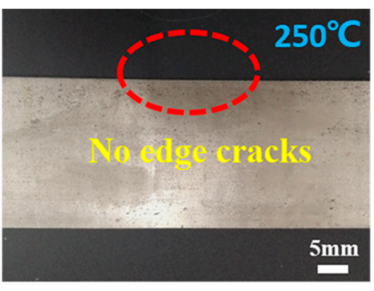

(c)

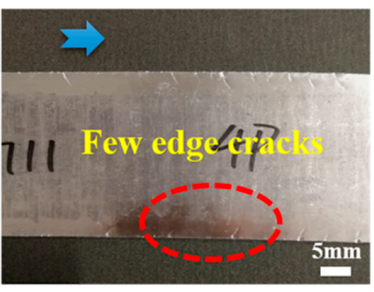

(f)

Figure 3. The appearance of the rolled sheets using on-line heating at different temperatures: (a) $150{ }^{\circ} \mathrm{C}$, (b) $200^{\circ} \mathrm{C}$, and (c) $250{ }^{\circ} \mathrm{C}$. The appearance of the rolled sheets using conventional rolling at different temperature: (d) $150{ }^{\circ} \mathrm{C}$, (e) $200{ }^{\circ} \mathrm{C}$, and (f) $250{ }^{\circ} \mathrm{C}$.

This phenomenon may be attributed to the extent of the dynamic recrystallization (DRX) and the homogeneity of deformation. Moreover, these two parameters mainly depended on the rolling temperature. Furthermore, the large edge cracks that appeared at low temperature may have also been caused by the formation of twins. Pekguleryuz et al. [8] confirmed by transmission electron microscope (TEM) that the profuse twins emerged after rolling at $150{ }^{\circ} \mathrm{C}$, resulting in the severe edge crack.

The statistical data of the number of edge cracks (the edge per $100 \mathrm{~mm}$ on each sheet) and the maximum crack depth for different rolling processes are presented in Figure 4 . The methods of counting crack numbers and measuring the maximum crack depth are illustrated in Figure 4a. The number of cracks was the total quantities of cracks calculated by counting the cracks from left to right at the edge of the sheet per $100 \mathrm{~mm}$. The maximum crack depth refers to the vertical distance from the edge to the tip of the largest crack. 


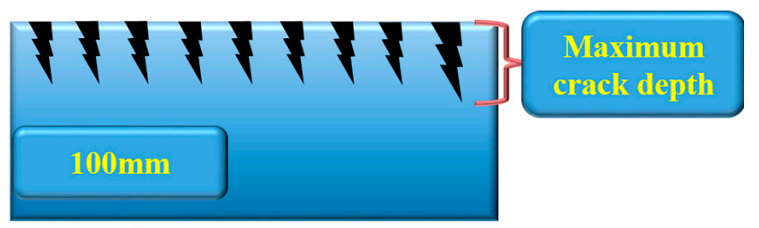

(a)

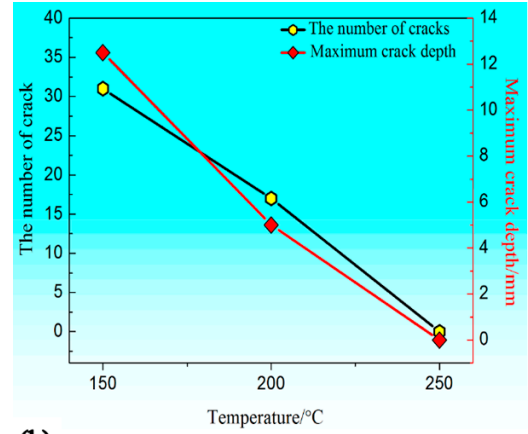

(b)

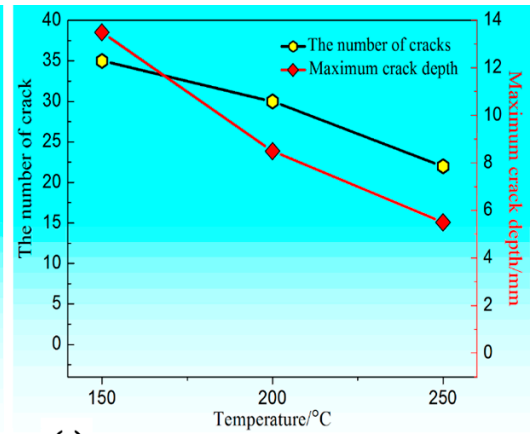

(c)

Figure 4. (a) Schematic showing counting of the crack numbers and measure the maximum crack depth, and the statistical data of the number of edge cracks and maximum crack length at different temperature for $(\mathbf{b})$ on-line heating rolling and (c) conventional rolling.

The result shows that the quantities and maximum depth of the cracks decreased with increasing rolling temperature in both on-line heating rolling and conventional rolling. It can also be seen that the number of cracks in the on-line heating process decreased more rapidly than that in conventional rolling, as shown in Figure $4 \mathrm{~b}, \mathrm{c}$. The maximum crack depth presented the same trend. It demonstrates that rolling temperature played a key role in the improvement of formability for $\mathrm{Mg}$ alloys. Ion et al. [19] showed that it is easy for $\mathrm{Mg}$ alloys to deform at elevated temperatures. Generally, the $\mathrm{Mg}$ alloy sheet can be rolled without edge cracks above $450{ }^{\circ} \mathrm{C}$ using conventional rolling. Our work indicated that the AT11M magnesium alloy sheets were successfully rolled without visible edge cracks under a temperature as low as $250{ }^{\circ} \mathrm{C}$ and a high pass reduction of $25 \%$ using on-line heating rolling.

In addition, the on-line heating rolling took much less time than the conventional rolling process. The rolling process of four passes using on-line heating rolling only took around $10 \mathrm{~min}$, while it took at least $60 \mathrm{~min}$ (including the annealing time) to accomplish the four passes using the traditional process. The detailed edge cracks of rolled sheets is presented in Figure 5. It can be seen that the width and depth of cracks decreased with the increase of temperature and no microcracks were observed at the rolling temperature of $250{ }^{\circ} \mathrm{C}$.

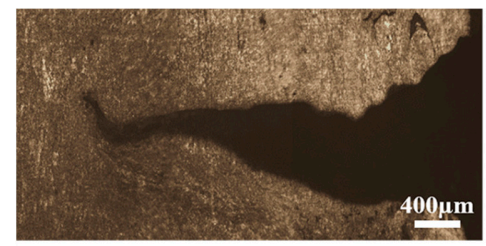

(a)

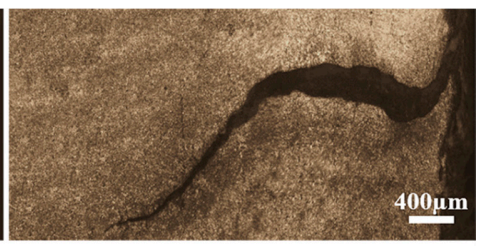

(b)

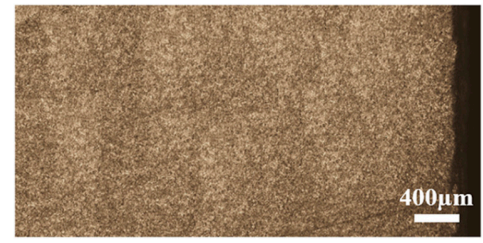

(c)

Figure 5. The optical micrograph of the edge cracks of the sheets rolled at different temperatures: (a) $150{ }^{\circ} \mathrm{C}$, (b) $200{ }^{\circ} \mathrm{C}$, and (c) $250{ }^{\circ} \mathrm{C}$. 


\subsection{Microstructures}

The typical optical micrographs in the central area of the rolled sheets using on-line heating rolling at different temperatures are shown in Figure 6. A large amount of dynamic recrystallized fine grains were formed and exhibited a non-uniform microstructure at a temperature of $150{ }^{\circ} \mathrm{C}$, as shown in Figure 6a. Some elongated original parent grains (pointed by the red circles) and twins (as blue arrows display in Figure $6 a, b$ ) were also observed at this low temperature.

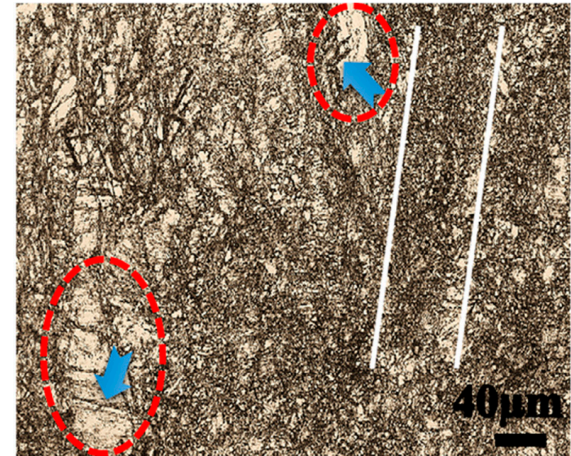

(a)

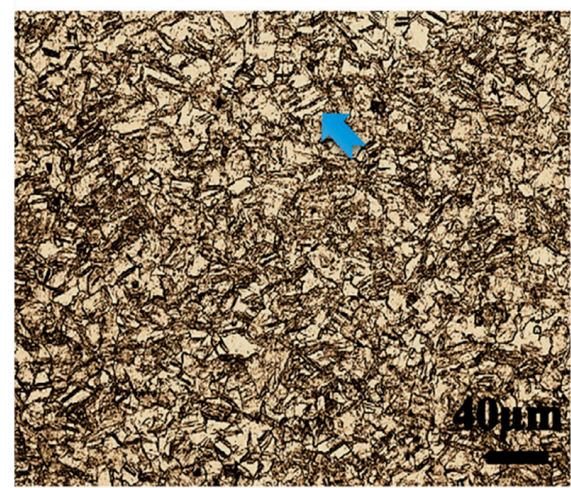

(c)

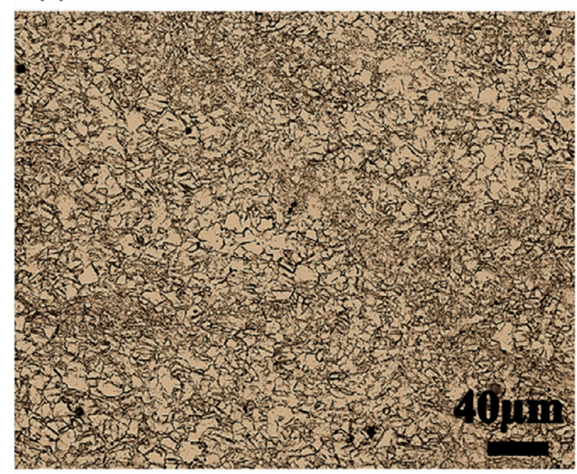

(e)

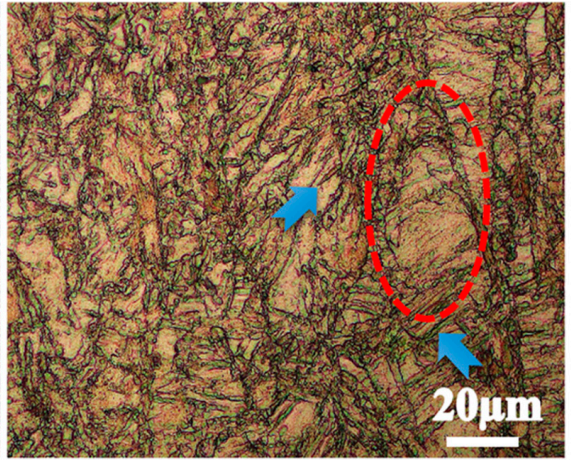

(b)

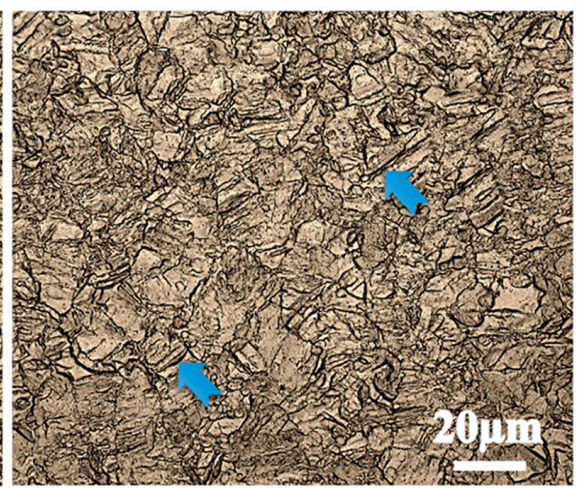

(d)

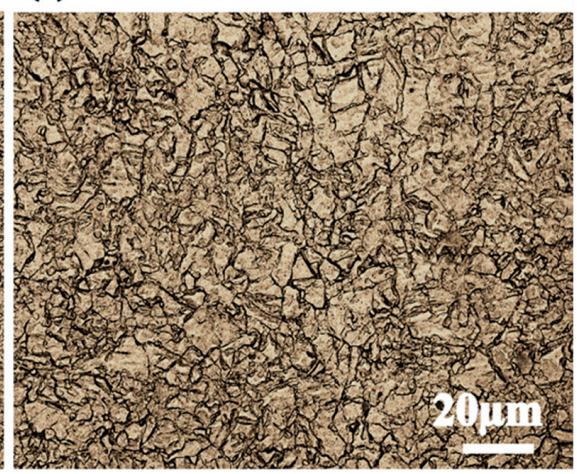

(f)

Figure 6. The optical micrographs of rolled sheets using on-line heating at different temperatures: (a) $150{ }^{\circ} \mathrm{C}$, (c) $200{ }^{\circ} \mathrm{C}$, and (e) $250{ }^{\circ} \mathrm{C}$, and (b,d,f) are the magnified microstructure corresponding to $(\mathbf{a}, \mathbf{c}, \mathbf{e})$, respectively.

The shear band (identified between white straight lines in Figure 6a) caused by local dynamic recrystallization and twinning were also observed. At first, large quantities of twins formed to coordinate the deformation. Then, the twins interacted with each other and generated local high energy regions containing a plethora of dislocations [19]. At last, local DRX took place at these areas with the high-density dislocation and some restored deformation energy, resulting in the formation 
of new local recrystallized grains ("initial soft area"). Kavyani et al. [20] studied the rolling behavior of AZ31 plates at elevated temperatures and revealed the important role of twins in recrystallization during processing. With the increase of strain, the soft area ultimately evolved into the shear band and formed the inhomogeneous microstructure [21,22].

As the rolling temperature rose, the number of twins and the average grain size decreased. No obvious twins are observed in Mg-1Al-1Sn-Mn alloy sheets rolled at $250{ }^{\circ} \mathrm{C}$, as shown in Figure $6 \mathrm{e}, \mathrm{f}$. In addition, the microstructure became more uniform at high rolling temperatures. The observed twins and severe edge cracks in the sheets rolled at $150{ }^{\circ} \mathrm{C}$ agreed well with the Pekguleryuz et al.'s research [8] that twins are related to the severe edge crack.

The fracture surface of the edge crack for the plates rolled at $150{ }^{\circ} \mathrm{C}$ and $200{ }^{\circ} \mathrm{C}$ are represented in Figure 7. It can be seen that there were many cleavages on the fracture surface of the rolled sheet at a low temperature, which indicated the low plasticity and a clear characteristic of brittle fracture. With the increase of rolling temperature to $200{ }^{\circ} \mathrm{C}$, a large number of dimples and tearing ridges appeared on the fracture surface, and the plasticity for the samples had improved for high rolling temperatures.

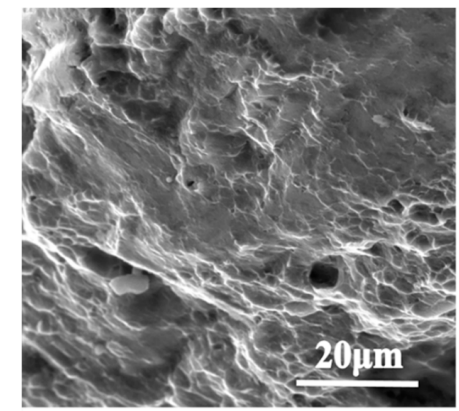

(a)

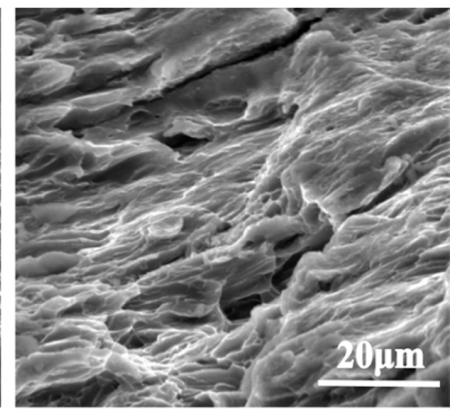

(b)

Figure 7. The fracture surfaces of the edge crack for plates rolled at different temperatures: (a) $150{ }^{\circ} \mathrm{C}$ and (b) $200{ }^{\circ} \mathrm{C}$.

\subsection{Texture Evolution}

The macrotextures of as-extruded and as-rolled samples at different temperatures were analyzed, as shown in Figure 8. The texture of the extruded samples is shown in Figure 8a, where it can be seen that the basal texture is presented, and the maximum basal texture intensity was 7.264. She et al. [17] revealed that ATM110 bars obtain a typical ring-fiber texture for as-extruded Mg alloy bars (basal plane parallel to the extrusion direction).

The texture reported in their work was different from that in this work. This could be due to the formation of dynamic recrystallization, resulting from a different shaping cross-section, extrusion temperature, and extrusion ratio. The samples were extruded into bars with the extrusion temperature of $300{ }^{\circ} \mathrm{C}$ and extrusion ratio of 25:1 in She et al.'s work [17], while our samples were extruded into plates with the extrusion temperature of $370{ }^{\circ} \mathrm{C}$ and extrusion ratio of $28: 1$. In the present study, the extruded plates with a strong basal texture were used as the raw materials for the subsequent on-line rolling process. The predominant basal texture was owed to the combined results of twinning, which could rotate the basal plane parallel to the extrusion, and dynamic recrystallization during large strain extrusion $[23,24]$.

For the rolled samples, the maximum basal texture intensity increased from 4.982 to 9.596 as the rolling temperature increased from $150{ }^{\circ} \mathrm{C}$ to $250{ }^{\circ} \mathrm{C}$, as displayed in Figure 8 . This phenomenon is consistent with the texture evolution trend of other rolled magnesium alloys [25,26]. Generally, during rolling, the $c$-axes of grains in great numbers are reoriented parallel to the compressive stress, which makes the basal plane align with the rolling direction of the plate, leading to a high anisotropy of the sheet. In the case of a c-axis parallel to the compressive axis, it is favorable for these grains to bring about twinning to coordinate the deformation among neighboring grains. However, for high 
temperature rolling, other deformation mechanisms (such as prismatic slip and pyramidal slip) can be activated with the aim of accommodating further deformation $[27,28]$. This is because the critical resolved shear stress (CRSS) of non-basal slip decreases with the increasing temperature.

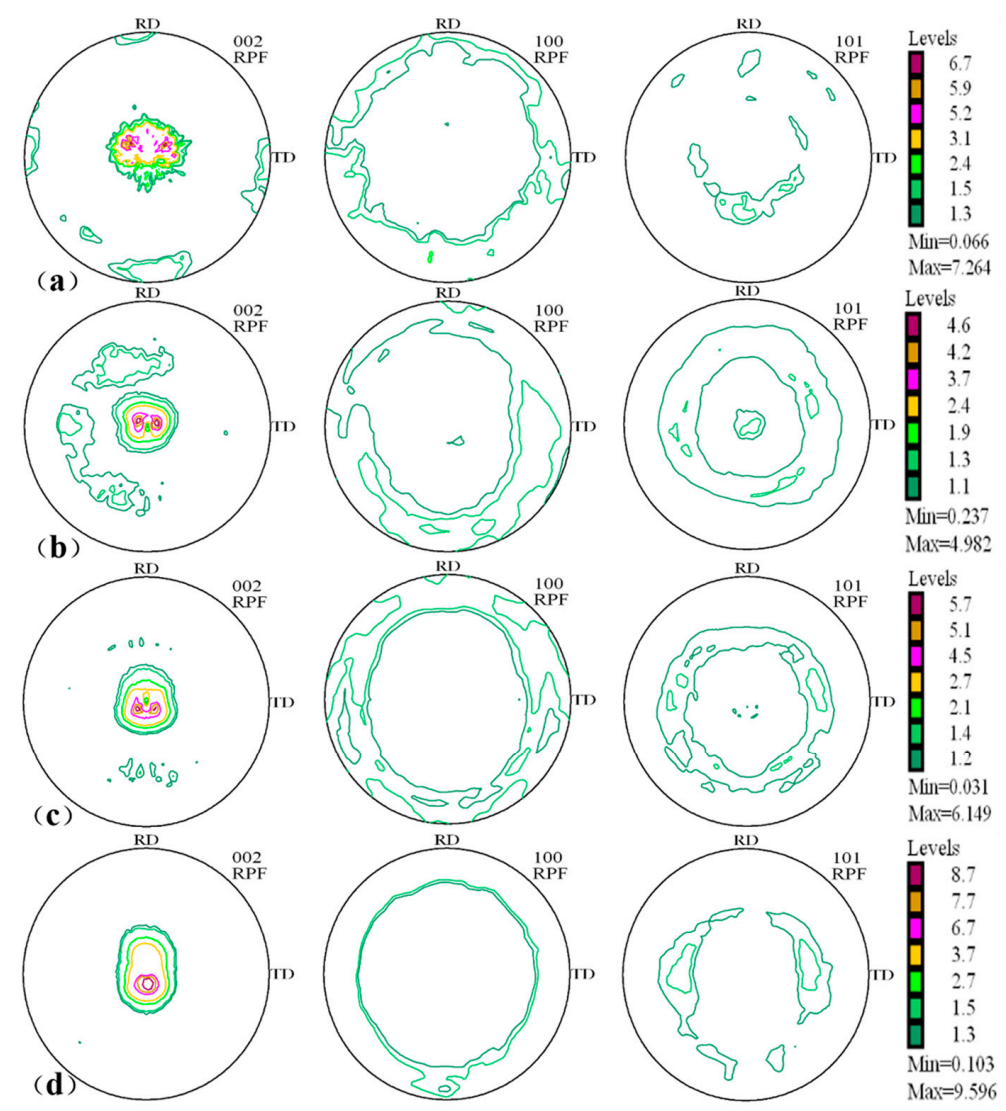

Figure 8. The pole figures of AT11M alloy sheets: (a) as-extruded, (b) rolled at $150{ }^{\circ} \mathrm{C},(\mathbf{c})$ rolled at $200{ }^{\circ} \mathrm{C}$, and (d) rolled at $250{ }^{\circ} \mathrm{C}$.

It can be observed that the basal pole of sample expresses a trend to split towards the rolling direction $(\mathrm{RD})$ as the rolling temperature increases, which was prevalent during the hot rolling process of Mg alloys. Li and Qi [29] have demonstrated that the RD spreading of basal poles was the result of the activation of pyramidal $<\mathrm{a}+\mathrm{c}>$ slips via simulations and experiments. In this case, the splitting of the basal pole may be related to the activation of pyramidal $<c+a>$ slips when the sheet was manufactured at high temperatures using on-line heating rolling [30]. Meanwhile, the tension imposed at both ends may have also exerted an impact to the splitting of the texture [31].

However, the texture examined using XRD can only reflect the macrotexture features. In this work, in order to investigate the microtexture characteristics and dynamic recrystallization after on-line heating rolling, the rolled specimens at $250{ }^{\circ} \mathrm{C}$ were chosen to conduct further analysis in detail due to its homogeneous structure. EBSD technology was utilized to analyze the microtexture characteristics with the aim to further study the DRX behavior and grain distribution. The orientation imaging maps, misorientation angle maps, and the (0001) pole figures of as-extruded and as-rolled sheets were compared in Figure 9. As seen in Figure 9a, the as-extruded AT11M sheet exhibits inhomogeneous grain distribution, which consists of original parent grains, as well as fine and coarse dynamic recrystallization grains. However, the microstructure turned into uniform grain distribution and the grains became more equiaxed after being rolled at $250{ }^{\circ} \mathrm{C}$ by on-line heating rolling, as shown in Figure 9d. 

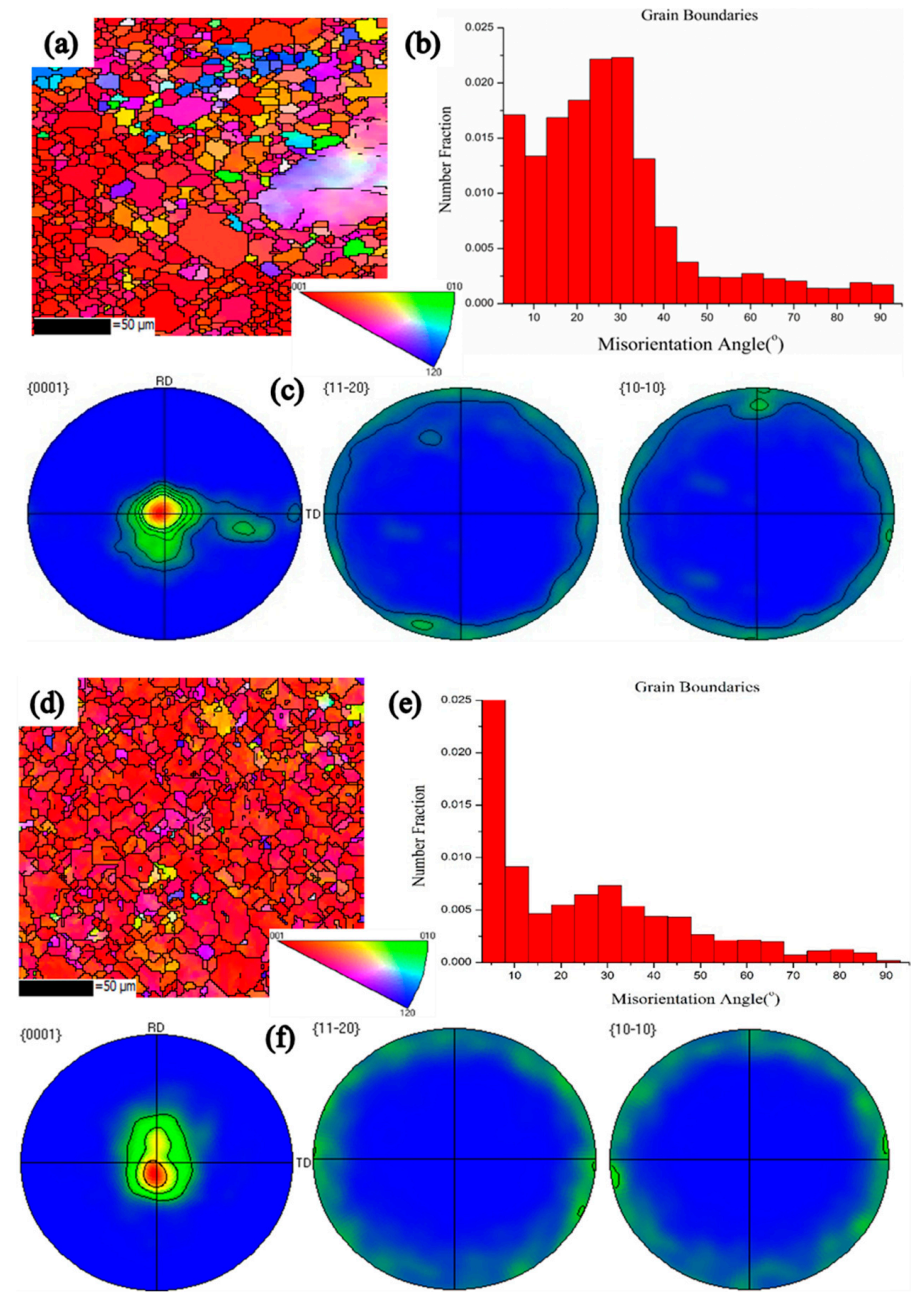

Figure 9. The orientation imaging maps of (a) as-extruded and (d) as-rolled sheets, the misorientation angle maps of (b) as-extruded and (e) as-rolled sheets, and pole figure maps of (c) as-extruded and (f) as-rolled sheets.

The grains in different colors stand for different orientations and no obvious twins appeared, demonstrating that the dynamic recrystallization had fully taken place during extrusion that produced the newborn DRX grains with random orientations. The twins had transformed into the new grains via nucleation and growth. The large amount of red-colored grains observed in both extruded and rolled states indicate the identical grain orientation. In other words, their c-axes were almost perpendicular to the extrusion or rolling direction. Rolling processes resulted in extremely high amounts of red grains, which is because new grains would rotate, and the c-axis would align parallel to the compression axis as strain increased [32]. It can also be noticed that there is only a small amount of DRX grains around parent grains in Figure 9d.

The misorientation angle of the extruded sample and rolled samples are shown in Figure 9b,e. It depicts that the fraction of grains containing high angle grain boundaries (HAGBs) in the extruded sample was much higher than that in rolled ones. It also revealed that the average misorientation angle decreased through the rolling process. In general, the low angle grain boundaries (LAGBs) turns into the HAGBs via an extended recovery and continuous DRX process [33]. The low number of HAGBs in the rolled sample indicated that only a partial dynamic recrystallization took place during rolling process.

Pole figure maps of the basal plane are presented in Figure $9 \mathrm{c}, \mathrm{f}$. The polar axis of the basal tilted to the RD after rolling as shown in Figure 9f, which was similar to the macrotexture evolution. This phenomenon was attributed to the activation of the pyramidal slip. Dynamic recrystallization 
maps in both the extruded and rolled state were also characterized though an EBSD technique, as shown in Figure 10. The grains colored using yellow, red, and blue colors represent the sub-grains, deformed grains, and recrystallized grains, respectively. It can be observed that dynamic recrystallization occurred in plenty of grains in the extruded state. There were also some super-fine new grains surrounding the coarse dynamic recrystallization grains, forming the uneven microstructure, as shown in Figure 10a. Besides, some deformed grains and a small amount of sub-grains appeared as well due to extrusion at a relatively high temperature. In the case of the rolling samples, dynamic recrystallization only occurred in partial grains, and a majority of deformed grains still remained. Moreover, only a few the sub-grains appeared after the rolling process, as displayed in Figure 10b.

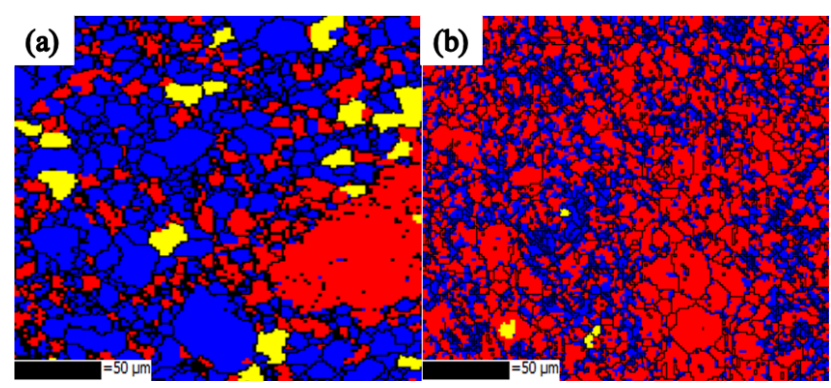

Figure 10. EBSD maps distinguishing the DRX region (blue area), sub-grains region (yellow area), and deformed region (red area) for (a) as-extruded and (b) as-rolled samples.

\subsection{Mechanical Properties}

The representative strain-stress curve of the as-extruded and as-rolled sample sheets are displayed in Figure 11. The tensile strength of the on-line heating rolled samples was significantly improved. However, the elongation decreased, and the detailed data are listed in Table 3. Stronger anisotropy was found in rolled sheets compared to that in extruded ones.

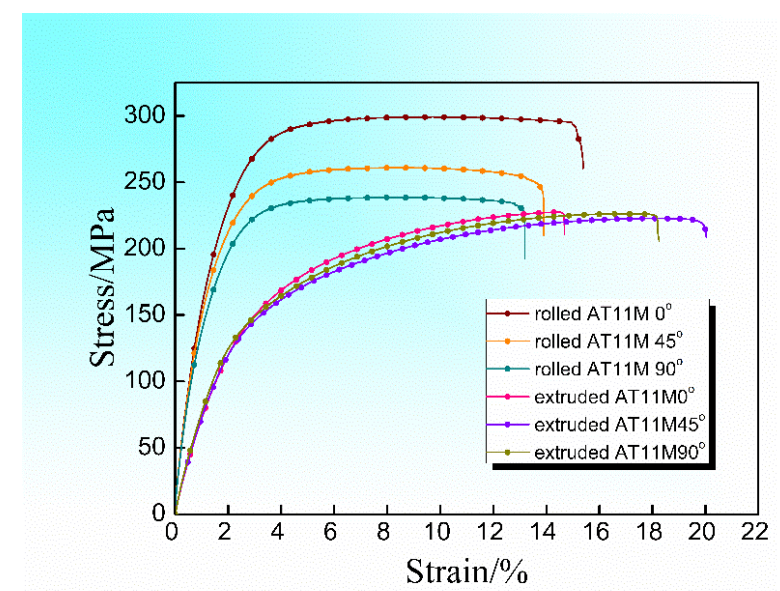

Figure 11. The curves of mechanical properties of sheets rolled at $250{ }^{\circ} \mathrm{C}$ and as-extruded.

Table 3. Mechanical properties of as-rolled at $250{ }^{\circ} \mathrm{C}$ and as-extruded Mg-1Al-1Sn-Mn sheets.

\begin{tabular}{cccccccccc}
\hline \multirow{2}{*}{ AT11M } & \multicolumn{3}{c}{ YS (MPa) } & \multicolumn{3}{c}{ UTS (MPa) } & \multicolumn{3}{c}{ EL (\%) } \\
\cline { 2 - 9 } & $\mathbf{0}^{\circ}$ & $\mathbf{4 5}^{\circ}$ & $\mathbf{9 0}^{\circ}$ & $\mathbf{0}^{\circ}$ & $\mathbf{4 5}^{\circ}$ & $\mathbf{9 0}^{\circ}$ & $\mathbf{0}^{\circ}$ & $\mathbf{4 5}^{\circ}$ & $\mathbf{9 0}^{\circ}$ \\
\hline Extruded & $84 \pm 4$ & $80 \pm 5$ & $70 \pm 1$ & $226 \pm 2$ & $223 \pm 1$ & $225 \pm 1$ & $14.8 \pm 0.5$ & $19.4 \pm 0.5$ & $17.9 \pm 1.2$ \\
As-Rolled & $148 \pm 6$ & $147 \pm 5$ & $136 \pm 9$ & $298 \pm 2$ & $261 \pm 2$ & $236 \pm 3$ & $14.6 \pm 0.7$ & $13.7 \pm 0.5$ & $13.6 \pm 2.2$ \\
\hline
\end{tabular}

The enhancement of strength from the extruded state to the rolled state in this study is attributed to: (1) the refinement of grains which can increase the strength through Hall Petch (H-P) formula, (2) the stronger texture in the rolled sheets [34], and (3) the larger amount of dislocations stored in 
the remaining deformed grains in the rolled samples. Pekguleryuz et al. [8] also showed that the yield strength increased with the fraction of deformed grains because of the high-density dislocations. The mechanical anisotropy at $250{ }^{\circ} \mathrm{C}$ was also due to the formation of a strong basal texture. The strong texture could also be a reason for the decreased elongation.

It is noted that the rolling direction (RD) possesses the optimal mechanical properties. Furthermore, the highest yield strength (YS) and ultimate tensile strength (UTS) were $148 \mathrm{MPa}$ and $298 \mathrm{MPa}$, respectively. In addition, the maximum elongation was $14.6 \%$ along the RD, as shown in Table 3. Figure $9 \mathrm{f}$ demonstrates that the $c$-axis of most of the rolled grains inclined towards RD. When the tensile tests were performed along RD at room temperature, the Schmid factor for basal slip reached the maximum and shear force operated on the basal planes to boost the slip. Therefore, the elongation was larger compared with those samples elongated along other directions.

\section{Discussion}

\subsection{Microstructure Evolution}

Both temperature and strain rate play a key role on the evolution of microstructures. The Zener-Hollomon parameter determines the influence of temperature and strain rate on hot deformation behavior. This parameter could be calculated using the following equation:

$$
Z=\hat{\varepsilon} \cdot \exp \left(\frac{Q}{R T}\right)
$$

in which $Z$ represents the Zener-Hollomon parameter, $\hat{\varepsilon}$ stands for the strain rate, $Q$ is the activation energy during hot deformation, $R$ is the gas constant $\left(8.314 \mathrm{~J} \cdot \mathrm{mol}^{-1} \cdot \mathrm{K}^{-1}\right)$, and $T$ is the absolute temperature [35]. Fatemi-Varzaneh et al. [36] reported that the microstructure becomes more uniform as the Zener-Hollomon parameter decreases. In this work, with the increase of temperature, the value of $Z$ diminished. As a consequence, the microstructure at higher rolling temperatures tended to be more uniform. At that time, a decrease in the flow stress appeared as a consequence of the deformation adiabatic heating and dynamic recrystallization during the process, which made the sample exhibit typical softening behavior and improved its formability.

\subsection{Edge Crack Formation}

The edge cracks in magnesium alloys can be recognized as a sort of damage, where the voids first appear and then expand into the cracks when the sheet is rolled at low temperature. As shown, there are still some smooth shear planes and obvious slip traces on the surface of the edge fracture, apart from a few voids in Figure $7 \mathrm{~b}$. The damage is a comprehensive result of the cavity spread, shear deformation, and strain accumulation at a low temperature. In this study, during the low-temperature rolling (at $150{ }^{\circ} \mathrm{C}$ ), a large number of twins that contain profuse dislocations, large original grains, and shear bands were formed at the edge of the plate subjected to the large strain deformation, which caused the internal microstructure to be extremely uneven, leading to the high energy area reserved in the plate. Furthermore, microcracks would have been easily generated owing to strain incompatibility either at the interface between twins and the matrix or the high energy areas, and would continue to expand by absorbing the reserved energy [37]. As a consequence, most of the energy was consumed in the form of microcrack expansion into edge cracks and lots of deformed grains.

The edge crack phenomenon could also be explained though the energy release across the edge section of the sheets. The rolling process of magnesium alloys could be regarded as a process of absorbing and releasing the energy. Twinning, DRX, and fracture (formation of cracks) were all methods used to release the deformation energy during the rolling process. Jones et al. [38] have exposed that the dynamic recrystallization (DRX) is an effective measure to consume the strain energy to coordinate deformation and absorb further strain. After the process of large strain rolling, a part of the energy is consumed through twinning and DRX. The leftover energy will release in the form 
of edge cracks. However, in this work, when the sheets were rolled at $250{ }^{\circ} \mathrm{C}$, under the same large strain rolling, high energy was also generated due to the severe deformation. However, there were still no visible edge cracks. This may be attributed to part of strain energy remaining in the deformed grains, and another part of deformation energy may be released via DRX to generate new grains and continuous recovery [39].

In summary, when the sheets were rolled at $250{ }^{\circ} \mathrm{C}$ using on-line heating rolling, the microstructure evolved to become more homogeneous and grains were largely refined after rolling. Average size was $31 \mu \mathrm{m}$ at extrusion and was refined to $15 \mu \mathrm{m}$ after rolling at $250{ }^{\circ} \mathrm{C}$, which could effectively impede the propagation of crack. Besides, the temperature at the edge section was higher than that rolled at $150{ }^{\circ} \mathrm{C}$ and $200{ }^{\circ} \mathrm{C}$. The high temperature could activate the non-basal slip and dynamic recrystallization to a larger extent, which resulted in high crack resistance. Furthermore, the high rolling temperature led to less twins, which would also prevent the initiation of cracks. Consequently, no cracks appeared in the sheets rolled at $250{ }^{\circ} \mathrm{C}$.

\section{Conclusions}

The edge crack, texture evolution, and mechanical properties of Mg-1Al-1Sn-Mn alloy sheets rolled using on-line heating rolling were studied. The following conclusions were found:

(1) Mg-1Al-1Sn-Mn alloy thin sheets were successfully prepared with large strain rolling (pass reduction as high as $25 \%$, with a total reduction of $\approx 67 \%$ by four passes) at a moderate temperature of $250{ }^{\circ} \mathrm{C}$ using on-line heating rolling. The rolled sheets showed no obvious edge cracks.

(2) A typical strong basal texture was formed during the rolling process leading to the mechanical anisotropy at a rolling temperature of $250^{\circ} \mathrm{C}$. In addition, the activation of $<\mathrm{c}+\mathrm{a}>$ pyramidal slips may be mainly responsible for the splitting of the basal poles of texture towards the rolling direction.

(3) Mg-1Al-1Sn-Mn alloy sheets rolled using the on-line heating exhibited good comprehensive mechanical properties: the yield strength (YS), ultimate tensile strength (UTS), and elongation along rolling direction were $148 \mathrm{MPa}, 298 \mathrm{Mpa}$, and 14.6\%, respectively. Furthermore, it has potential to be commercialized.

(4) The reason for no obvious edge cracks could be attributed to the homogeneous microstructure caused by grain refinement and the activation of non-basal slips at edge region in a larger extent at edge section. Furthermore, the decline of the stacking fault energy accompanying the addition of Sn element, as well as the softening behavior due to deformation adiabatic heating and dynamic recrystallization, may also be important factors for no edge cracks forming.

Author Contributions: Conceptualization, J.S. (Jiangfeng Song) and F.P.; data analysis, Q.L. and S.Z.; funding acquisition, J.S. (Jiangfeng Song); investigation and methodology, Q.L. and S.Z.; project administration, J.S. (Jiangfeng Song); supervision, J.S. (Jia She) and P.P.; writing-original draft, Q.L.; review and editing, J.S. (Jiangfeng Song) and J.S. (Jia She).

Funding: The present work was supported by the National Key Research and Development Program of China (No. 2016YFB0301100), the National Science Foundation for Young Scientists of China (No. 51701027), the Fundamental Research Funds for the Central Universities Project (No. 106112017CDJPT130001, No. 106112016CDJXZ138811, No. 0211005202111, No. 2018CDXYCL0018), and the Special major R \& D Projects for Key Technology Innovation of Key Industries in Chongqing (Grant No. cstc2017zdcy-zdzxX0006).

Acknowledgments: The authors acknowledge the Research Group of National Engineering Research Center for Magnesium Alloys at Chongqing University.

Conflicts of Interest: The authors declare no conflicts of interest. 


\section{References}

1. Mordike, B.L.; Ebert, T. Magnesium: Properties applications-Potential. Mater. Sci. Eng. A 2001, 302, 37-45. [CrossRef]

2. You, S.; Huang, Y.; Kainer, K.U.; Hort, N. Recent research and developments on wrought magnesium alloys. J. Magnes. Alloys 2017, 5, 239-253. [CrossRef]

3. Polmear, I.J. Magnesium alloys and applications. Met. Sci. J. 1994, 10, 1-16. [CrossRef]

4. Alaneme, K.K.; Okotete, E.A. Enhancing plastic deformability of $\mathrm{Mg}$ and its alloys-A review of traditional and nascent developments. J. Magnes. Alloys 2017, 5, 460-475. [CrossRef]

5. Pekguleryuz, M.O. Current developments in wrought magnesium alloys. Adv. Wrought Magnes. Alloys 2012, 3-62. [CrossRef]

6. Parks, D.M.; Ahzi, S. Polycrystalline plastic deformation and texture evolution for crystals lacking five independent slip systems. J. Mech. Phys. Solids 1990, 38, 701-724. [CrossRef]

7. Matsubara, K.; Miyahara, Y.; Horita, Z.; Langdon, T.G. Achieving enhanced ductility in a dilute magnesium alloy through severe plastic deformation. Metall. Mater. Trans. A 2004, 35, 1735-1744. [CrossRef]

8. Pekguleryuz, M.; Celikin, M.; Hoseini, M.; Becerra, A.; Mackenzie, L. Study on edge cracking and texture evolution during $150{ }^{\circ} \mathrm{C}$ rolling of magnesium alloys: The effects of axial ratio and grain size. J. Alloys Compd. 2012, 510, 15-25. [CrossRef]

9. Emley, E.F. Principles of Magnesium Technology; Pergamon Press: Oxford, UK, 1966.

10. Yoo, M.H.; Agnew, S.R.; Morris, J.R.; Ho, K.M. Non-basal slip systems in HCP metals and alloys: Source mechanisms. Mater. Sci. Eng. A 2001, 319-321, 87-92. [CrossRef]

11. Koike, J.; Kobayashi, T.; Mukai, T.; Watanabe, H.; Suzuki, M.; Maruyama, K.; Higashi, K. The activity of non-basal slip systems and dynamic recovery at room temperature in fine-grained AZ31B magnesium alloys. Acta Mater. 2003, 51, 2055-2065. [CrossRef]

12. Agnew, S.R.; Duygulu, Ö. Plastic anisotropy and the role of non-basal slip in magnesium alloy AZ31B. Int. J. Plast. 2005, 21, 1161-1193. [CrossRef]

13. Catorceno, L.L.C.; de Abreu, H.F.G.; Padilha, A.F. Effects of cold and warm cross-rolling on microstructure and texture evolution of AZ31B magnesium alloy sheet. J. Magnes. Alloys 2018, 6, 121-133. [CrossRef]

14. Wang, H.Y.; Zhang, N.; Wang, C.; Jiang, Q.C. First-principles study of the generalized stacking fault energy in Mg-3Al-3Sn alloy. Scr. Mater. 2011, 65, 723-726. [CrossRef]

15. Saboori, A.; Dadkhah, M.; Pavese, M.; Manfredi, D.; Biamino, S.; Fino, P. Hot deformation behavior of Zr- $1 \% \mathrm{Nb}$ Alloy: Flow Curve Analysis and Microstructure Observations. Mater. Sci. Eng. A 2017, 696, 366-373. [CrossRef]

16. Pan, F.; Zeng, B.; Jiang, B.; Zhang, M.; Dong, H. Enhanced mechanical properties of AZ31B magnesium alloy thin sheets processed by on-line heating rolling. J. Alloys Compd. 2017, 693, 414-420. [CrossRef]

17. She, J.; Pan, F.; Zhang, J.; Tang, A.; Luo, S.; Yu, Z.; Song, K.; Rashad, M. Microstructure and mechanical properties of Mg-Al-Sn extruded alloys. J. Alloys Compd. 2016, 657, 893-905. [CrossRef]

18. Guan, M.; Hu, Y.; Zheng, T.; Zhao, T.; Pan, F. Composition Optimization and Mechanical Properties of Mg-Al-Sn-Mn Alloys by Orthogonal Design. Materials 2018, 11, 1424. [CrossRef] [PubMed]

19. Ion, S.E.; Humphreys, F.J.; White, S.H. Dynamic recrystallisation and the development of microstructure during the high temperature deformation of magnesium. Acta Metall. 1982, 30, 1909-1919. [CrossRef]

20. Kavyani, M.; Ebrahimi, G.R.; Sanjari, M.; Haghshenas, M. Texture evaluation in warm deformation of an extruded Mg-6Al-3Zn alloy. J. Magnes. Alloys 2016, 4, 89-98. [CrossRef]

21. Zhang, H.; Jin, W.; Fan, J.; Cheng, W.; Roven, H.J.; Xu, B.; Dong, H. Grain refining and improving mechanical properties of a warm rolled AZ31 alloy plate. Mater. Lett. 2014, 135, 31-34. [CrossRef]

22. Wang, Y.; Xin, Y.; Yu, H.; Lv, L.; Liu, Q. Formation and microstructure of shear bands during hot rolling of a Mg-6Zn-0.5Zr alloy plate with a basal texture. J. Alloys Compd. 2015, 644, 147-154. [CrossRef]

23. Valle, J.A.D.; Pérez-Prado, M.T.; Ruano, O.A. Texture evolution during large-strain hot rolling of the $\mathrm{Mg}$ AZ61 alloy. Mater. Sci. Eng. A 2003, 355, 68-78. [CrossRef]

24. Liu, Q.; Zhou, X.; Zhou, H.; Fan, X.; Liu, K. The effect of extrusion conditions on the properties and textures of AZ31B alloy. J. Magnes. Alloys 2017, 5, 202-209. [CrossRef]

25. Sun, H.; Liang, S.; Wang, E. Mechanical properties and texture evolution during hot rolling of AZ31 magnesium alloy. Trans. Nonferr. Met. Soc. China 2009, 19, s349-s354. [CrossRef] 
26. Yan, Y.; Luo, J.; Zhang, J.; Zhuang, L. Study on the microstructural evolution and mechanical properties control of a strong textured AZ31 magnesium alloy sheet during cryorolling. Acta Metall. Sin. 2017, 53, 107-113.

27. Huang, X.; Suzuki, K.; Chino, Y.; Mabuchi, M. Influence of initial texture on rolling and annealing textures of Mg-3Al-1Zn alloy sheets processed by high temperature rolling. J. Alloys Compd. 2012, 537, 80-86. [CrossRef]

28. Wang, J.; Zhang, X.; Lu, X.; Yang, Y.; Wang, Z. Microstructure, texture and mechanical properties of hot-rolled Mg-4Al-2Sn-0.5Y-0.4Nd alloy. J. Magnes. Alloys 2016, 4, 207-213. [CrossRef]

29. Li, X.; Qi, W. Effect of initial texture on texture and microstructure evolution of ME20 Mg alloy subjected to hot rolling. Mater. Sci. Eng. A 2013, 560, 321-331. [CrossRef]

30. Jia, W.P.; Hu, X.D.; Zhao, H.Y.; Ju, D.Y.; Chen, D.L. Texture evolution of AZ31 magnesium alloy sheets during warm rolling. J. Alloys Compd. 2015, 645, 70-77. [CrossRef]

31. Li, X.; Al-Samman, T.; Gottstein, G. Mechanical properties and anisotropy of ME20 magnesium sheet produced by unidirectional and cross rolling. Mater. Des. 2011, 32, 4385-4393. [CrossRef]

32. Fu, X.S.; Yang, Q.; Sun, W.; Lu, S.J.; Chen, G.Q.; Zhou, W.L. Multi-pass large strain rolling of as-cast AZ31 magnesium alloy. Met. Sci. J. 2016, 32, 1869-1876. [CrossRef]

33. Jin, L.; Lin, D.; Mao, D.; Zeng, X.; Chen, B.; Ding, W. Microstructure evolution of AZ31 Mg alloy during equal channel angular extrusion. Mater. Sci. Eng. A 2006, 423, 247-252. [CrossRef]

34. Tripathi, A.; Murty, S.V.S.N.; Narayanan, P.R. Microstructure and texture evolution in AZ31 magnesium alloy during caliber rolling at different temperatures. J. Magnes. Alloys 2017, 5, 340-347. [CrossRef]

35. Ammouri, A.H.; Kridli, G.; Ayoub, G.; Hamade, R.F. Relating grain size to the Zener-Hollomon parameter for twin-roll-cast AZ31B alloy refined by friction stir processing. J. Mater. Process. Technol. 2015, 222, 301-306. [CrossRef]

36. Fatemi-Varzaneh, S.M.; Zarei-Hanzaki, A.; Beladi, H. Dynamic recrystallization in AZ31 magnesium alloy. Mater. Sci. Eng. A 2007, 456, 52-57. [CrossRef]

37. Barnett, M.R. Twinning and the ductility of magnesium alloys: Part I: “Tension" twins. Mater. Sci. Eng. A 2007, 464, 1-7. [CrossRef]

38. Jones, A.R. Annealing twinning and the nucleation of recrystallization at grain boundaries. J. Mater. Sci. 1981, 16, 1374-1380. [CrossRef]

39. Rodriguez, A.K.; Ayoub, G.A.; Mansoor, B.; Benzerga, A.A. Effect of strain rate and temperature on fracture of magnesium alloy AZ31B. Acta Mater. 2016, 112, 194-208. [CrossRef] 